\title{
Characterization of overactive bladder in women in a primary care setting
}

\author{
This article was published in the following Dove Press journal: \\ Open Access Journal of Urology \\ 22 March 20II \\ Number of times this article has been viewed
}

\author{
Wellman W Cheung' \\ Dorota Borawski² \\ Ovadia Abulafia ${ }^{2}$ \\ Miriam T Vincent ${ }^{3}$ \\ Miriam Harel' \\ Martin H Bluth ${ }^{4}$ \\ 'Department of Urology, \\ ${ }^{2}$ Department of Obstetrics \\ and Gynecology, ${ }^{3}$ Department \\ of Family Practice, SUNY Downstate \\ Medical Center, Brooklyn, New York; \\ ${ }^{4}$ Department of Pathology, \\ Wayne State University/Detroit \\ Medical Center, Detroit, MI, USA
}

Correspondence: Wellman W Cheung SUNY Downstate Medical Center, Departments of Urology and Obstetrics/Gynecology,

450 Clarkson Avenue, Brooklyn, NY I I 230, USA

Tel +l 7188532828

$\mathrm{Fax}+\mathrm{I} 7189750040$

Email wellman.cheung@downstate.edu
Background: Overactive bladder (OAB) represents a disorder with overall increasing prevalence in the American population. However, gender-specific characteristics of OAB and how it relates to the general practitioner are not well described. We sought to determine the distribution and characteristics of OAB in women in a primary care setting.

Methods: Self-administered questionnaires were distributed to patients visiting a family medicine outpatient center. The modified questionnaire included eight questions on evidence of lower urinary tract symptoms (LUTS, OAB-validated 8-question screener [OAB-V8]), two questions on stress urinary incontinence, and one question on incomplete emptying. The questionnaire included demographic characteristics and relevant medical and surgical history. Body mass index was calculated based on weight and height. Chi-square test and risk ratio analysis were used to analyze the relationship between $\mathrm{OAB}$ and other independent variables.

Results: Of 1025 questionnaires administered, 386 were completed. Patients ranged from 16 to 97 years, the majority were African American (78.2\%), and 49.7\% were premenopausal while $50.3 \%$ were postmenopausal. $\mathrm{OAB}$ was present in $46.4 \%$ of premenopausal women and $41.7 \%$ of postmenopausal women. $\mathrm{OAB}$ was significantly associated with overweight status (body mass index 25.0-29.9, $P=0.042$ ) and obesity (body mass index $\geq 30, P<0.001$ ). Overall, obese women were twice as likely to have OAB (relative risk $=1.99,1.31-3.04$ ) than women with normal weight. OAB was not shown to correlate with race, cigarette use, history of hysterectomy, or parity.

Conclusion: $\mathrm{OAB}$ was evident in $44 \%$ of all female patients surveyed, which is much higher than previously reported estimates. In addition, overweight women were more likely to have $\mathrm{OAB}$. Increased awareness of $\mathrm{OAB}$ in the primary care setting should be considered for women's general health.

Keywords: overactive bladder, incontinence, women, primary care

\section{Introduction}

According to the International Continence Society, overactive bladder (OAB) is characterized by urinary urgency, with or without urge incontinence, usually with frequency and nocturia, in the absence of causative infection or pathological conditions, and represents a spectrum of disorders with a range of presentations and management options. ${ }^{1-7}$ According to a population-based survey of 16,776 men and women aged 40 years and older conducted by Milsom et al ${ }^{5}$ in six countries, by telephone or direct interview, the prevalence of OAB in Europe has been estimated to be $15.6 \%$ in men and $17.4 \%$ in women. The National Overactive BLadder Evaluation survey (NOBLE), in which 11,740 Americans agreed to participate, found the overall prevalence of OAB to be $16.9 \%$ in women and $16.0 \%$ in men. ${ }^{2} \mathrm{OAB}$ negatively affects quality of life and 
carries a large psychosocial and economic burden, ${ }^{1-3}$ because such increased awareness of OAB is important for appropriate intervention towards quality of life improvement. However, gender-specific awareness in a general physicians practice is not well described, and the disorder may be underdiagnosed. ${ }^{4}$ We sought to determine the prevalence and characteristics of $\mathrm{OAB}$ in women in a primary care setting.

\section{Methods}

Over a three-month period, 1025 self-administered questionnaires on urinary symptoms were distributed to patients over 16 years of age who visited a family medicine outpatient center while waiting to be seen by their primary care physician. ${ }^{6}$ In total, 525 patients agreed to participate in this study, of which $386(73.5 \%)$ were women. This study was granted exemption by the Institutional Review Board of the relevant institution.

The modified questionnaire included eight questions on evidence of lower urinary tract symptoms (LUTS) using the Overactive Bladder-Validated 8-question screener [OAB-V8], ${ }^{6,8}$ two questions on stress urinary incontinence, and one question on incomplete emptying of the bladder after urination. Responses were answered on a 6-point symptom bother scale ranging from 0 (not at all) to 5 (a great deal). An additional question was asked about the effect of urinary symptoms on quality of life, with answers ranging from 0 (delighted) to 6 (terrible). The questionnaire also included data on demographic characteristics and relevant medical and surgical history. Patient weight and height were measured for calculating body mass index $\left(\mathrm{kg} / \mathrm{m}^{2}\right)$.

Primary care physicians then reviewed the questionnaire with their patients at the end of the visit, and reported on exit clinical diagnoses, whether they detected any urinary symptoms, whether the symptoms were detected before or after reviewing the questionnaire, and whether they would treat or refer the patient to a specialist. These questions were similar to those used in a study to assess physician awareness of urinary symptoms. ${ }^{5}$

Patients were considered to have OAB if their OAB-V8 score was $\geq 8 .{ }^{8}$ Positive OAB-V8 scores were categorized into three levels of severity, ie, $8-10,11-13$, and $\geq 14$. The presence of specific LUTS was then analyzed. The criteria for LUTS and OAB subtypes are shown in Table 1. Patients who did not complete the OAB-V8 and stress urinary incontinence questions were excluded from the study. Patients were categorized into age groups of $<25,25-34,35-44,45-54$, 55-64, 65-74, and $\geq 75$ years. Women were considered to be premenopausal if they were younger than 55 years of age and postmenopausal if older than 55 years.
Table I Criteria for lower urinary tract symptoms and overactive bladder subtypes

\begin{tabular}{|c|c|}
\hline & Identification criteria \\
\hline \multicolumn{2}{|l|}{ LUTS } \\
\hline Urgency & $\begin{array}{l}\text { Answer } \geq I \text { to any one of the three } \\
O A B-V 8 \text { questions on urge to urinate }\end{array}$ \\
\hline Frequency & $\begin{array}{l}\text { Answer } \geq I \text { to any one of the two } \\
O A B-V 8 \text { questions on frequent urination }\end{array}$ \\
\hline Nocturia & $\begin{array}{l}\text { Answer } \geq I \text { to the OAB-V8 question } \\
\text { on nocturia }\end{array}$ \\
\hline UUI & $\begin{array}{l}\text { Answer } \geq I \text { to one of the two OAB-V8 } \\
\text { questions on urine leakage associated } \\
\text { with urge }\end{array}$ \\
\hline SUI & $\begin{array}{l}\text { Answer } \geq I \text { to one of the two questions } \\
\text { on urine leakage associated with physical } \\
\text { activities, sneezing, coughing, or laughing }\end{array}$ \\
\hline MUI & $\begin{array}{l}\text { Meet the criteria for both UUI } \\
\text { and SUI described above }\end{array}$ \\
\hline Incomplete emptying & $\begin{array}{l}\text { Answer } \geq I \text { to the question on incomplete } \\
\text { emptying }\end{array}$ \\
\hline \multicolumn{2}{|c|}{ OAB subtypes (based on presence of above symptoms) } \\
\hline OAB-F & $\begin{array}{l}\text { OAB-V8 score } \geq 8 \text { with symptoms of } \\
\text { frequency and/or nocturia only }\end{array}$ \\
\hline OAB-U & $\begin{array}{l}\text { OAB-V8 score } \geq 8 \text { with symptoms of } \\
\text { urgency without incontinence }\end{array}$ \\
\hline OAB-UUI & $\begin{array}{l}\text { OAB-V8 score } \geq 8 \text { with symptoms of UUI } \\
\text { and no SUI }\end{array}$ \\
\hline OAB-SUI & $\begin{array}{l}\text { OAB-V8 score } \geq 8 \text { with symptoms of SUI } \\
\text { and no UUl }\end{array}$ \\
\hline OAB-MUI & OAB-V8 score $\geq 8$ with symptoms of MUI \\
\hline
\end{tabular}

Abbreviations: $\mathrm{OAB}$, overactive bladder; LUTS, lower urinary tract symptoms; $\mathrm{UUI}$, urge urinary incontinence; MUI, mixed urinary incontinence; SUI, stress urinary incontinence; $\mathrm{OAB}-\mathrm{V} 8$, overactive bladder validated 8-question screener; $\mathrm{F}$, frequency alone; $\mathrm{U}$, urgency without incontinence.

\section{Statistical analysis}

The Chi-square test was used to determine statistically significant differences between the premenopausal and postmenopausal groups. To determine the relationship between OAB prevalence and other factors (race, body mass index, parity, history of smoking, and history of hysterectomy), covariates were first evaluated using the Chi-square test. Statistically significant $(P<0.05)$ covariates then underwent risk ratio (RR) analysis. Patients were excluded if they did not report on the variable to be analyzed. Results are presented as RR and 95\% confidence interval (CI). All statistical analyses were performed using SPSS software (v.14.0 for Windows; SPSS Inc, Chicago, IL).

\section{Results}

Nineteen patients were excluded from the study due to incomplete answers on the OAB-V8 and stress urinary incontinence questionnaires, yielding a final group of 386 women in the current analysis. Table 2 reports the 
Table 2 Characteristics of participants

\begin{tabular}{|c|c|c|c|c|c|c|}
\hline \multirow{2}{*}{$\begin{array}{l}\text { Characteristic, n (\%) } \\
\text { Age, years }\end{array}$} & \multicolumn{2}{|c|}{ Premenopause $(n=192)$} & \multicolumn{2}{|c|}{ Postmenopause $(n=194)$} & \multicolumn{2}{|c|}{ Total $(n=386)$} \\
\hline & & & & & & \\
\hline$<25$ & 23 & $(12.0)$ & - & - & 23 & $(6.0)$ \\
\hline $25-34$ & 50 & $(26.0)$ & - & - & 50 & $(13.0)$ \\
\hline $35-44$ & 46 & $(24.0)$ & - & - & 46 & (II.9) \\
\hline $45-54$ & 73 & $(38.0)$ & - & - & 73 & $(18.9)$ \\
\hline $55-64$ & - & - & 72 & $(37.1)$ & 72 & $(\mid 8.7)$ \\
\hline $65-74$ & - & - & 79 & $(40.7)$ & 79 & (20.5) \\
\hline$\geq 75$ & - & - & 43 & $(22.2)$ & 43 & $(I I .1)$ \\
\hline \multicolumn{7}{|l|}{ Race } \\
\hline Black & 157 & $(81.8)$ & 145 & $(74.7)$ & 302 & $(78.2)$ \\
\hline Hispanic & 18 & $(9.4)$ & 20 & $(10.3)$ & 38 & $(9.8)$ \\
\hline White & 3 & $(1.6)$ & 3 & $(1.5)$ & 6 & $(1.6)$ \\
\hline Other/not stated & 14 & (7.3) & 26 & $(13.4)$ & 40 & $(10.4)$ \\
\hline \multicolumn{7}{|l|}{ Education } \\
\hline Less than high school & 4 & $(2.1)$ & 17 & $(8.8)$ & 21 & $(5.4)$ \\
\hline High school graduate & 58 & $(30.2)$ & 73 & $(37.6)$ & $13 \mid$ & (33.9) \\
\hline Some college/college graduate & 66 & $(34.4)$ & 18 & $(9.3)$ & 84 & $(21.8)$ \\
\hline Graduate school & 18 & $(9.4)$ & 9 & $(4.6)$ & 27 & $(7.0)$ \\
\hline Not stated & 46 & $(24.0)$ & 77 & $(39.7)$ & 123 & $(31.9)$ \\
\hline \multicolumn{7}{|l|}{ Body mass index, $\mathrm{kg} / \mathrm{m}^{2}$} \\
\hline$<25.0$ & 36 & $(18.8)$ & 31 & $(16.0)$ & 67 & $(17.4)$ \\
\hline $25.0-29.9$ & 45 & $(23.4)$ & 62 & $(32.0)$ & 107 & $(27.7)$ \\
\hline$\geq 30$ & 79 & $(4 I . I)$ & 74 & $(38.1)$ & 153 & (39.6) \\
\hline Not stated & 32 & $(16.7)$ & 27 & $(13.9)$ & 59 & $(15.3)$ \\
\hline \multicolumn{7}{|l|}{ History of smoking } \\
\hline Yes & 57 & $(29.7)$ & 53 & $(27.3)$ & 110 & $(28.5)$ \\
\hline No & 135 & $(70.3)$ & $|4|$ & $(72.7)$ & 276 & (71.5) \\
\hline \multicolumn{7}{|l|}{ Parity } \\
\hline$<2$ & 63 & $(32.8)$ & 29 & $(14.9)$ & 92 & $(23.8)$ \\
\hline $2-4$ & 87 & $(45.3)$ & 86 & $(44.3)$ & 173 & $(44.8)$ \\
\hline$\geq 5$ & 35 & $(18.2)$ & 66 & $(34.0)$ & 101 & $(26.2)$ \\
\hline \multicolumn{7}{|l|}{ Previous surgical history } \\
\hline Bladder surgery & 4 & $(2.1)$ & 10 & $(5.2)$ & 14 & (3.6) \\
\hline Urinary leakage surgery & 1 & $(0.5)$ & 2 & $(1.0)$ & 3 & $(0.8)$ \\
\hline Hysterectomy & 13 & $(6.8)$ & 63 & $(32.5)$ & 76 & $(19.7)$ \\
\hline \multicolumn{7}{|l|}{$\mathrm{OAB}$ status } \\
\hline Normal & 103 & $(53.6)$ & 113 & $(58.2)$ & 216 & $(56.0)$ \\
\hline OAB with UI & 75 & $(39.1)$ & 65 & $(33.5)$ & 140 & $(36.3)$ \\
\hline OAB without UI & 14 & (7.3) & 16 & $(8.2)$ & 30 & (7.8) \\
\hline
\end{tabular}

Abbreviations: $\mathrm{OAB}$, overactive bladder; UI, urinary incontinence; BMI, body mass index.

characteristics of the women studied, including age, ethnicity, education, body mass index, parity, smoking, prior surgical history, and OAB status. Patients ranged from 16 to 97 years, the majority were African American (78.2\%), and $49.7 \%$ of all the women were premenopausal and $50.3 \%$ were postmenopausal.

Age-specific distribution of $\mathrm{OAB}$ and $\mathrm{OAB}$ subtypes are shown in Figures 1 and 2. Evidence of general OAB did not vary much with age (Figure 1). However the prevalence of $\mathrm{OAB}$ with urgency subtype (OAB-U) was greatest (16\%) in the 45-54-year age group (Figure 2), whereas $\mathrm{OAB}$ subtypes including those with urge urinary incontinence and mixed urinary incontinence were $\leq 5 \%$ among all age groups. As shown in Table 2, OAB was present in $46.4 \%$ of premenopausal women ( \pm urinary incontinence) and $41.7 \%$ of postmenopausal women.

Of the women surveyed, 216 women did not meet a diagnosis of $\mathrm{OAB}$, of whom 103 were premenopausal and 113 postmenopausal. Among the premenopausal women without OAB, LUTS reported were frequency (57.3\%), nocturia $(48.5 \%)$, and urgency $(22.3 \%)$, whereas for postmenopausal women, urinary frequency was reported in $63.7 \%$, nocturia in $58.4 \%$, and urgency was present in $23.0 \%$ (Table 3). Urge urinary incontinence was present in $38.5 \%$ of 


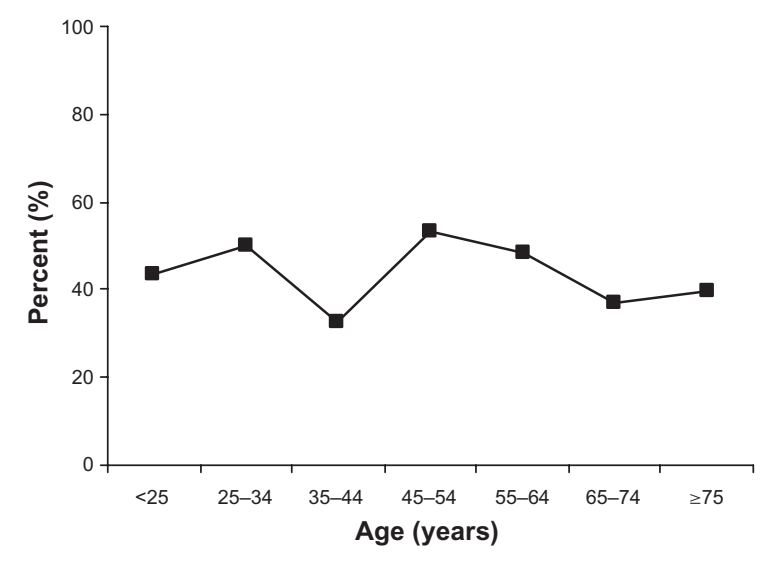

Figure I Distribution of overactive bladder by age.

postmenopausal women and stress urinary incontinence was present in $22.1 \%$ (data not shown, $P>0.05$ ).

OAB was significantly associated with overweight (body mass index 25.0-29.9) in women $(P=0.042)$ and obesity (body mass index $\geq 30, P<0.001$, Table 4 ). However, when menopause status was controlled, this association was only found in obese premenopausal women $(P<0.001)$, who had a greater than two-fold increased risk for $\mathrm{OAB}(\mathrm{RR}=2.43$, 1.34-4.40). Overall, obese women were twice as likely to have OAB $(\mathrm{RR}=1.99,1.31-3.04)$ than women of normal weight $(P<0.001)$.

Interestingly, $\mathrm{OAB}$ was significantly associated with incomplete bladder emptying $(P<0.001)$ and with stress urinary incontinence $(P<0.001)$ in both pre- and postmenopausal women; OAB was not shown to vary with race, cigarette use, history of hysterectomy, or parity in women (data not shown).

\section{Discussion}

In this study, we found an OAB distribution among women in a primary care setting that is more than double that reported

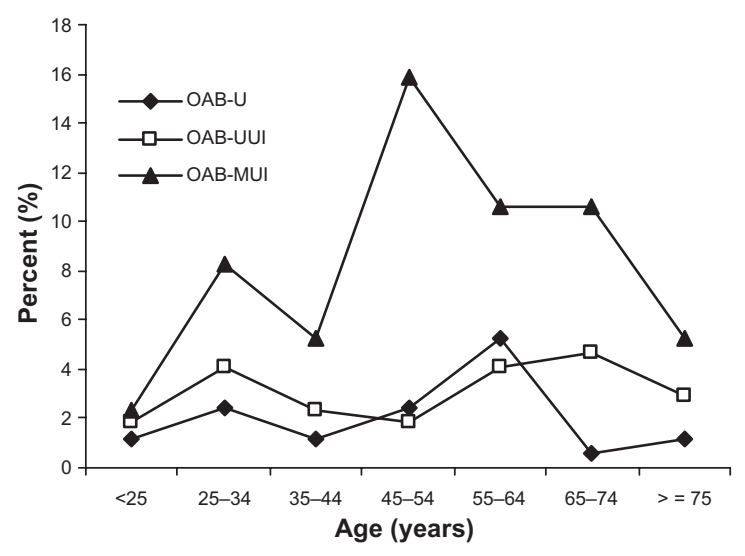

Figure 2 Distribution of overactive bladder subtypes by age.
Table 3 Distribution of lower urinary tract in women without overactive bladder by menopausal status

\begin{tabular}{lll}
\hline $\mathbf{n}(\%)$ & $\begin{array}{l}\text { Premenopause } \\
(\mathbf{n}=103)\end{array}$ & $\begin{array}{l}\text { Postmenopause } \\
(\mathbf{n}=1 \text { I 3) }\end{array}$ \\
\hline Symptoms & & \\
Frequency & $59(57.3)$ & $72(63.7)$ \\
Nocturia & $50(48.5)$ & $66(58.4)$ \\
Urgency & $23(22.3)$ & $26(23.0)$ \\
\hline
\end{tabular}

in a recent US population-based study. ${ }^{2}$ Unlike the previous population-based studies, ${ }^{2,7}$ in which responses regarding LUTS were elicited from noninstitutionalized individuals through telephone interviews, our questionnaire relies on self-report by primary care outpatients and review by primary care physicians at the conclusion of the visit. Thus, our data collection method resembles an office-based primary care physician study, ${ }^{5}$ which had an OAB prevalence estimate that was highest $(26.5 \%)$ and more closely resembles our results. In the studies cited above, OAB was defined based on the presence and/or frequency of specific LUTS, while in our study, OAB criteria are based on scoring on a symptom bother scale. Furthermore, the populations in the previously cited studies were predominantly white, while our patient population was mostly African American. These differences may contribute to the discrepancy in OAB prevalence found in our study compared with the prevalence previously reported.

We find that $\mathrm{OAB}$ with incontinence is more common than OAB without incontinence in both pre- and postmenopausal women. Most studies on female urinary incontinence have reported stress urinary incontinence as being more common than urge urinary incontinence, ${ }^{5}$ especially in younger women, ${ }^{9,10}$ while mixed urinary incontinence was the major

Table 4 Relative risk for overactive bladder by body mass index category

\begin{tabular}{llll}
\hline Comparison group* & \multicolumn{2}{l}{ Risk ratio** } & \\
\cline { 2 - 4 } & Relative risk & $\mathbf{9 5 \%} \mathbf{C l}$ & $\mathbf{P}$ \\
\hline All women & & & \\
BMI 25.0-29.9 & 1.57 & $0.96-2.46$ & 0.042 \\
BMI $\geq 30.0$ & 1.99 & $1.31-3.04$ & $<0.00$ I \\
Premenopausal women & & & \\
BMI 25.0-29.9 & - & - & 0.221 \\
BMI $\geq 30.0$ & 2.43 & $1.34-4.40$ & $<0.00$ I \\
Postmenopausal women & & & \\
BMI 25.0-29.9 & - & - & 0.134 \\
BMI $\geq 30.0$ & - & - & 0.108 \\
\hline
\end{tabular}

Notes: *Women in the corresponding age group with $\mathrm{BMI}<25$ served as the reference group; **Risk ratio was calculated only when $P<0.05$; risk ratio $=$ prevalence of overactive bladder in women with comparison BMI/prevalence of overactive bladder in women with reference BMI of $<25$.

Abbreviations: $\mathrm{BMI}$, body mass index; $\mathrm{Cl}$, confidence interval. 
presentation overall. ${ }^{5,9,10} \mathrm{We}$ find that most women with $\mathrm{OAB}$ have $\mathrm{OAB}$-mixed urinary incontinence, whereas urge urinary incontinence and $\mathrm{OAB}$-urge urinary incontinence are more prevalent than stress urinary incontinence and OAB-stress urinary incontinence in women with $\mathrm{OAB}$. These findings are supported by others ${ }^{11,12}$ who have reported black women to have lower rates of stress urinary incontinence but higher rates of urge urinary incontinence than white women. The significant association between $\mathrm{OAB}$ and stress urinary incontinence we found is also supported. ${ }^{10}$

We find a significant association between $\mathrm{OAB}$ and incomplete emptying of the bladder in both pre- and postmenopausal women which could be related to a variety of factors. ${ }^{13-16}$ Although bladder outlet obstruction leading to incomplete emptying is commonly seen in benign prostatic hyperplasia in older men, ${ }^{15}$ the relationship between $\mathrm{OAB}$ and incomplete emptying in women may involve mechanisms other than obstruction. ${ }^{13}$

Obesity as a risk factor for $\mathrm{OAB}^{2,10}$ and urinary incontinence ${ }^{9,14,17}$ have been previously reported. The risk for OAB we found for all obese women (1.99) is similar to that reported by Stewart et $\mathrm{al}^{2}(2.2)$ in obese women with OAB-urge urinary incontinence. However, contrary to earlier reports, ${ }^{2,5,7}$ we do not find OAB prevalence to increase with advancing age in women. We also do not find any significant association between $\mathrm{OAB}$ and smoking, although some studies have demonstrated that smoking may be a risk factor for urinary incontinence. ${ }^{14,17}$ Additionally, we do not find any significant association between $\mathrm{OAB}$ and hysterectomy in pre- or postmenopausal women. However, some previous studies have demonstrated that hysterectomy increased the risk for urge urinary incontinence ${ }^{18}$ but not stress urinary incontinence. ${ }^{18,19}$ Hysterectomy is thought to contribute to urinary incontinence through pelvic nerves or pelvic floor damage.

When interpreting the results of this study, several limitations should be considered. Language barriers, patient trust concerns, and cultural differences pose challenges in implementing a questionnaire-based study. Furthermore, women may report precipitancy (an impending feeling of incontinence) with stress urinary incontinence, which might be interpreted as urgency and this would be exacerbated in obese women, for simple biomechanical reasons. Nonetheless, measures were taken to ensure that questionnaires were distributed to all eligible patients who visited the clinic in an effort to minimize overestimation of response. However, a self-selection bias may be present, given that patients with LUTS may be more inclined to complete the questionnaire than those without any symptoms. Because the majority of our participants were African American, it is difficult to draw any conclusions about racial differences in the prevalence of OAB.

\section{Conclusion}

OAB was evident in $44 \%$ of all female patients in our study, which is a number much higher than previously reported estimates. Increasing the awareness of $\mathrm{OAB}$ among primary care physicians, and adopting clinical tools, such as a reliable and valid screening questionnaire, may aid in increasing the detection and treatment of $\mathrm{OAB}$.

\section{Disclosure}

The authors report no conflicts of interest in this work.

\section{References}

1. Abrams P, Kelleher CJ, Kerr LA, Rogers RG. Overactive bladder significantly affects quality of life. Am J Manage Care. 2000;6: S580-S590.

2. Stewart WF, Van Rooyen JB, Cundiff GW, et al. Prevalence and burden of overactive bladder in the United States. World J Urol. 2003;20: $327-336$.

3. Hu TW, Wagner TH, Bentkover JD, et al. Estimated economic costs of overactive bladder in the United States. Urology. 2003;61: 1123-1128.

4. Abrams P, Cardozo L, Fall M. The standardization of terminology of lower urinary tract function: Report from the standardization subcommittee of the International Continence Society. Neurourol Urodyn. 2002;21:167-178.

5. Goepel M, Hoffmann JA, Piro M, Rubben H, Michel MC. Prevalence and physician awareness of symptoms of urinary bladder dysfunction. Eur Urol. 2002;41:234-239.

6. Cheung WW, Blank W, Borawski D, Tran W, Bluth MH. Prevalence of overactive bladder, its under-diagnosis, and risk factors in a male urologic veterans population. Int J Med Sci. 2010;7:391-394.

7. Milsom I, Abrams, P, Cardozo L, Roberts RG, Thüroff JW, Wein AJ. How wide-spread are the symptoms of an overactive bladder and how are they managed? A population-based prevalence study. BJU Int. 2001; $87: 760-766$

8. Coyne K, Margolis M, Zyczynski T, Elinoff V, Roberts RG. Validation of an OAB Screener in a primary care patient population in the US. Presented at the International Continence Society and IUCA 2004 Scientific Programme. Paris, France, August 25-27, 2004.

9. Melville JL, Katon W, Delaney K, Newton K. Urinary incontinence in US women: A population-based study. Arch Intern Med. 2005;165: 537-542.

10. Teleman PM, Lidfelt J, Nerbrand C, Samsioe G, Mattiasson A; WHILA study group. Overactive bladder: Prevalence, risk factors and relation to stress incontinence in middle-aged women. BJOG. 2004;111:600-604.

11. Thom DH, Van den Eeden SK, Ragins AI, et al. Differences in prevalence of urinary incontinence by race/ethnicity. J Urol. 2006;175: 259-264.

12. Brown JS, Grady D, Ouslander JG, Herzog AR, Varner RE, Posner SF. Prevalence of urinary incontinence and associated risk factors in postmenopausal women. Heart \& Estrogen/Progestin Replacement Study (HERS) Research Group. Obstet Gynecol. 1999;94:66-70.

13. Grodstein F, Fretts R, Lifford K, Resnick N, Curhan G. Association of age, race, and obstetric history with urinary symptoms among women in the Nurses' Health Study. Am J Obstet Gynecol. 2003;189:428-434. 
14. Sampselle CM, Harlow SD, Skurnick J, Brubaker L, Bondarenko I. Urinary incontinence predictors and life impact in ethnically diverse perimenopausal women. Obstet Gynecol, 2002;100:1230-1238.

15. Knutson T, Edlund C, Fall M, Dahlstrand C. BPH with coexisiting overactive bladder dysfunction - an everyday urological dilemma. Neurourol Urodyn. 2001;20:237-247.

16. Mostwin JL. Pathophysiology: The varieties of bladder overactivity. Urology. 2002;60:22-26.

17. Hannestad YS, Rortveit G, Daltveit AK, Hunskaar S. Are smoking and other lifestyle factors associated with female urinary incontinence? The Norwegian EPINCONT study. BJOG. 2003;110:247-254.
18. van der Vaart CH, van der Bom JG, de Leeuw JR, Roovers JP, Heintz AP. The contribution of hysterectomy to the occurrence of urge and stress urinary incontinence symptoms. BJOG. 2002;109:149-154.

19. de Tayrac R, Chevalier N, Chauveaud-Lambling A, Gervaise A, Fernandez H. Risk of urge and stress urinary incontinence at long-term follow-up after vaginal hysterectomy. Am J Obstet Gynecol. 2004;191: 90-94.

\section{Publish your work in this journal}

The Open Access Journal of Urology is an international, peer-reviewed, open access journal publishing original research, reports, editorials, reviews and commentaries on all aspects of adult and pediatric urology in the clinic and laboratory including the following topics: Pathology, pathophysiology of urological disease; Investigation and treatment of

\section{Dovepress}

urological disease; Pharmacology of drugs used for the treatment of urological disease. The manuscript management system is completely online and includes a very quick and fair peer-review system, which is all easy to use. Visit http://www.dovepress.com/testimonials.php to read real quotes from published authors.

Submit your manuscript here: http://www.dovepress.com/open-access-journal-of-urology-journal 